\title{
L. On the influence of pressure on certain cases of electrical conduction and decomposition
}

\author{
J.W. Clark
}

To cite this article: J.W. Clark (1885) L. On the influence of pressure on certain cases of electrical conduction and decomposition, Philosophical Magazine Series 5, 20:126, 435-439, DOI: $10.1080 / 14786448508627781$

To link to this article: http://dx.doi.org/10.1080/14786448508627781

册 Published online: 29 Apr 2009.

Submit your article to this journal $[\pi$

Џ Article views: 2

Q View related articles $\square$ 
from the sheet itself or from the portion of the sheet which coincides sensibly with the tangent plane at the place considered, or from an infinite plane sheet coinciding with that tangent plane. This is on the assumption that the part of the sheet which coincides sensibly with the tangent plane is of large dimensions compared with the thickness of the dielectric, $i$. e. that the latter is small compared with any radius of curvature of the sheet.

The result obtained therefore holds for curved double sheets as well as plane ones.

Now, if a curved sheet be under a uniform surface-tension $\mathrm{T}$, it is well known that the stress experienced by any element $\delta S$ of its surface is along the normal, and equal to

$$
\mathrm{T}\left(\frac{1}{\mathrm{R}_{1}}+\frac{1}{\mathrm{R}_{2}}\right) \delta \mathrm{S}
$$

$R_{1}, R_{2}$ being the principal radii of curvature where $\delta S$ is situated. When we apply this to the electrical double layer, we obtain the same result as comes from the direct expression, on Green's theory, of the force exerted by the electrical system on the two charged faces which belong to the element $\delta \mathrm{S}$.

For a single curved electrified layer of finite dimensions, open or closed, the surface-tension is different at different points, and at the same point across different lines on the surface; except in the case of an electrified spherical sheet, in which it is easily seen to be constant and equal to $-\pi \rho^{2} a$, where $a$ is the radius of the sphere.

September 11, 1885.

L. On the Influence of Pressure on certain cases of Electrical Conduction and Decomposition. By J. W. ClaRK, Assistant Professor of Physics in University College, Liverpool*.

$A \mathrm{~S}$ the subject of electrolysis is to be brought prominently A before the next Meeting of the British Association, the following short outline of an investigation, commenced some years ago, may not be without interest at the present time.

The subject properly divides itself into three branches, viz.:the influence of pressure on the electrical conduction and decomposition of -

I. Dilute sulphuric acid (products of electrolysis occupying much greater volume than when combined to form the electrolyte).

II. A solution of (e.g.) $\mathrm{CuSO}_{4}$ (products of electrolysis * Communicated by the Author. 
occupying about the same volume as when combined to form the electrolyte).

III. The conduction of mercury.

Of these three classes, it will be noticed that the liquids in I. and II. are composed of complex molecules which, according to Clausius, are in a state of continuous motion varied by collisions with one another which cause dissociation*. Mercury, on the other hand, is a metallic conductor, and a liquid which is usually regarded as being composed of simple or monatomic molecules, which are therefore incapable of undergoing dissociation; but by the application of a sufficient external pressure its molecules may be brought nearer together, or, in other words, the lengths of the molecular mean free paths may be reduced.

The investigation to which I now wish to refer relates to the decomposition of dilute sulphuric acid under an external pressure which it is my object to make appreciable in comparison with the molecular forces of the liquid itself, for it is only when that condition is fulfilled that any direct results are to be anticipated such as those which are here sufficiently suggested by the questions:-Is Faraday's law independent of pressure? Do the conduction and decomposition of an electrolyte always vary together? Can electrolytic action be stopped by pressure? It was to obtain a reply to such questions that I turned from the region of speculation to the surer ground of experiment, and in the first instance set myself to measure the electrical resistance of acidulated water, and the amount of gas liberated from it by a known current under pressure.

The method of experiment in outline is as follows:-The dilute sulphuric acid to be electrolyzed is hermetically sealed in a short glass tube $(0 \cdot 1$ centim. in internal, and 0.7 centim. in external diameter), through the ends of which pass thin platinum-wire electrodes, of which the upper wire is usually so encased in glass that only the portion in the electrolyte is exposed : a precaution found to be necessary in order to avoid continuous recombination. This roughly describes the "electrolytic tube," in which the pressure upon the dilate sulphuric acid is generated by the gases liberated by the current as they accumulate in the (determined) volume of the tube which is unoccupied by the liquid. When the circuit includes a gal-

* If volatility and a large coefficient of expansion for heat may be regarded as a probable indication of a long mean free molecular path, it does not seem impossible, on the hypothesis of Clausius, that under the influence of a sufficiently great external pressure, such liquids as condensed gases $\left(\mathrm{CO}_{2}, \mathrm{NH}_{3}, \mathrm{SO}_{2}\right.$, \&c., fused $\left.\mathrm{HgCl}_{2}\right)$, might be rendered good electrical conductors, or at least have their conductivity increased. 
vanometer as well as a silver voltameter, variations of current, as well as total current, can be measured; and, finally, the quantity of gas liberated in the electrolytic tube under the accumulating pressure exerted by it upon the liquid is determined by allowing it to burst in a stoppered eudiometer (of special construction) over mercury, so that the whole of the gas is collected. From the volume of gas thus obtained the bursting or maximum pressure can be calculated.

The principal results may be very briefly stated as follows:-

1. When such an electrolytic tube containing dilute sulphuric acid is fixed in a vertical position, the lower electrode connected with the positive and the upper electrode with the negative pole of a battery, the evolution of gas appears to become less and less, and the electrical resistance of the contents of the tube increases, until, with an E.M.F. of 30 volts, the needle of a galvanometer in circuit shows only a very small deflection. This action appears to be due to the formation of very dense sulphuric acid $\left(\mathrm{H}_{2} \mathrm{SO}_{4}\right.$ ? $)$ at the + electrode at the bottom of the tube, whilst the water from which it has been separated forms a layer above it of so high resistance as to almost absolutely stop the passage of the current. This condition must not be mistaken for the cessation of electrolytic decomposition produced by pressure.

The strong acid is produced at the + electrode by the action of the current, and owing to the small sectional area of the tube, though it again mixes with the liquid above it by diffusion, it does so less rapidly than it is separated by the current. Moreover, under a sufficient pressure diffusive rate is lessened as the length of the mean free molecular path is decreased.

The above singular action affords a means of concentrating sulphuric acid without boiling.

2. When the poles are reversed, the dense sulphuric acid is formed by the current at the upper electrode, and thus becomes again mixed with the rest of the liquid in the tabe as it descends through the liquid, the mixing action being facilitated by the bubbles of hydrogen rising from the lower electrode. "In this way the separating action of the current is prevented, and my glass tubes (which burst at about 290 to 300 atmospheres) fail to withstand the pressure of the gases liberated by the current. I sought to strengthen one glass tube of special form by first coating it with pure silver by Martin's method, and then thickly electrotyping it with copper ; but it also burst. It is certain, therefore, that a pressure of 300 atmospheres is insufficient to arrest the electroly tic decomposition of dilnte sulphuric acid. I am not yet certain whether pressure exercises any direct influence on the

Phil. Mag. S. 5. Vol. 20. No. 126. Nov. 1885. 2 I 


\section{Pressure in Electrical Conduction and Decomposition.}

electrical resistance and on the quantity of gas liberated from dilute sulphuric acid, but what there is is slight. There seems to be a small decrease in the resistance, but I cannot yet say to what this is due ; for this part of the iuvestigation is incomplete, and it is exceedingly difficult to distinguish and separate between possible causes.

3. Ozone is present in the gases liberated by the bursting of the electroly tic tube. I have not estimated it quantitatively, but $I$ have no reason to think it present in unusual amount. Under some conditions, e. g. during the formation of ozone under the influence of the silent discharge, pressure might facilitate the condensation of oxygen to ozone.

It may, finally, be needful to increase the pressures employed in this investigation still more, and to employ vessels of steel or of some other material. The whole investigation is one of great difficulty, but I shall probably publish a fuller account of the methods and results of which the above forms a short and very imperfect summary*.

\section{Aldenda to the Author's paper "On certain Cases of Electro- lytic Decomposition," Phil. Mag, July 1885.}

Page 38, line 5 from top, omit binary.

Page 38, add:--Dr. Gore has discovered that heated argentic fluoride commences to conduct while still solid, and that when fused its electrical resistance is very small. He appears to regard the conduction in both cases as being unaccompanied by decomposition, i. e. non-electrolytic.

Page 43, line 15 from top, for (and $\mathrm{Hg}_{4} \mathrm{I}_{6}$ ) read (and $\mathrm{HgI}_{6}$ ?)

Page 39, line 6 from bottom, add:-It is of interest to remark, in connection with the electrolytic decomposition of glass at $100^{\circ} \mathrm{C}$., that $\mathrm{I}$ have recently learnt from Mr. Hicks that it may also be annealed at this temperature.

Pages 40 and 45, add:-Amongst the properties of fused

* To the proof I have an opportunity of adding that, since the above was written, I have found a short paper by $\mathrm{M}$. Bouvel in the Comptes Rendus, t. Ixxxvii. p. 1068, wherein he states that he has found experimentally that:-

(1) La décomposition de l'eau par un courant est indépendent de la pression.

(2) La quantité de l'électricité récessaire pour décompcser un même poids d'eau est sensiblement la même quelle que soit la pression à laquelle s'opère la décomposition.

M. Bouvel verified these statements up to 200 , and found that the decomposition was not stopped by a pressure of 360 atmospheres. 
mercuric iodide and chloride which led me to infer that the molecules of these substances may possess an unusually long mean free path of liquids, I omitted to mention their large coefficients of expansion for heat.

August 8, 1885.

LI. On the Winters of Great Britain and Ireland, as influenced by the Gulf-Stream. By Prof. Henry Hennessy, F.R.S.* $N$ the ninth volume of the Proceedings of the Royal 1 Society, p. 324, is printed a letter which I wrote to the late General Sir Edivard Sabine, on the influence of the Gulfstream on the winters of the British Islands. I pointed out that if abnormally cold or warm winters are due to changes in the condition of the comparatively tepid currents bathing our shores, then during cold winters the differences of temperature between the Northern and remaining coasts should be greater than during mild winters. A comparison of the observations made in the months of December 1855, 1856, and 1857 presented precisely this result. The winters of some recent years having exhibited abnormal features as to temperature, I have made a comparison of the results published by the Meteorological Office, of which the following may be taken as the leading facts.

In comparing the coast-temperatures of Great Britain, it should be remarked that the island is shaped in an irregular triangular outline, of which the summit is in North Scotland, and the base the south coast of England. For temperaturecomparisons it is therefore best to compare the South coast with the West coast and North-east coast.

In the winters of 1871 and 1881 the month of January was cold in Great Britain, and the following results have been grouped as indicated :-

\section{1. (Cold.)}

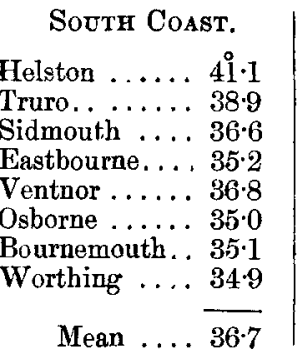

\section{West COAST.}

Barnstaple .... 3\% $37^{\circ} \cdot 0$

Llandudno .... $36 \cdot 1$

Liverpool .... 335

Cockermouth . . 33.7

Silloth $\ldots \ldots .33 \cdot 0$
North-East Coast.

Holkham .... 3: 3

Boston .... . 3 $31 \cdot 6$

Hull ....... 31·3

Whitby $\ldots, 31 \cdot 6$

Shields ...... $33 \cdot 0$

Excess of South over West coast........ $2 \cdot 0$

Excess of South over North-East coast .... $4 \cdot 8$

Communicated by the Author. 